\title{
Prognostic role of preoperative D-dimer, fibrinogen and platelet levels in patients with oral squamous cell carcinoma
}

\author{
Yu-jie Liang ${ }^{1,2}$, Xue-ying Mei ${ }^{1,2}$, Bin Zeng ${ }^{1,2}$, Si-en Zhang ${ }^{1,2}$, Le Yang ${ }^{1,2}$, Xiao-mei Lao ${ }^{1,2^{*}}$ (D) and Gui-qing Liao ${ }^{1,2^{*}}$
}

\begin{abstract}
Background: The relationship between cancer and coagulation has been intensively studied in recent years; however, the effects of coagulation factors on oral squamous cell carcinoma (OSCC) have rarely been reported. This study aimed to investigate the relationship between preoperative D-dimer (DD), fibrinogen (FIB), platelets (PLT) and OSCC, as well as the prognostic value of DD, FIB and PLT in OSCC.

Methods: We retrospectively investigated a total of 202 patients with OSCC treated at Guanghua Hospital of Stomatology, Sun Yat-sen University. Baseline demographic and clinicopathological information as well as both preoperative and postoperative DD, FIB and PLT results were collected from each patient, and patients with primary OSCC were followed up for disease progression, death or the end of the study. The correlations between preoperative DD, FIB, PLT and other clinical features, as well as the therapeutic effect and PFS were analysed statistically, and postoperative DD and surgical parameters were also analysed.

Results: Preoperative DD was significantly correlated with T stage, $\mathrm{N}$ stage, clinical stage and relapse of OSCC $(P=$ $0.000,0.001,0.000$ and 0.000 , respectively). Univariate Cox regression analyses showed that high preoperative DD predicted poor prognosis in patients with OSCC ( $H R=2.1, P=0.033)$, while FIB and PLT showed no prognostic values. Postoperative DD was significantly correlated with preoperative DD and surgical type but not the duration of surgery ( $P=0.005,0.001$ and 0.244 , respectively).

Conclusion: In this study, we suggested that high preoperative DD level may serve as an indicator for synchronous neck dissection in patients with $\mathrm{T}_{1,2}$ OSCC, and the elevated DD level might be the marker of disease progression in patient follow up.
\end{abstract}

Keywords: D-dimer, Fibrinogen, Platelets, Oral squamous cell carcinoma, Prognosis

\section{Background}

Oral squamous cell carcinoma (OSCC) is one of the most commonly seen malignancies in the head and neck region, and tumour cell proliferation and metastasis occur at high rates even at the very first stage of the primary tumour. Approximately one-half of patients are

\footnotetext{
* Correspondence: laoxm3@mail.sysu.edu.cn

'Department of Oral and Maxillofacial Surgery, Guanghua School of

Stomatology, Hospital of Stomatology, Sun Yat-sen University, 56 Lingyuanxi Road, Guangzhou 510055, Guangdong, China

Full list of author information is available at the end of the article
}

already in advanced stages of disease when diagnosed [1]. Despite remarkable advances in diagnostic techniques and therapeutic methods, the long-term survival rates of oral squamous cell carcinoma remain poor.

The correlation between cancer and hypercoagulation has been noticed since the nineteenth century, as global haemostasis is more frequently activated in patients with cancer, and much attention has been devoted to this research field. D-Dimer (DD) is a degradation product of the cross-linked fibrin polymer that is sensitive to both

C C The Author(s). 2021 Open Access This article is licensed under a Creative Commons Attribution 4.0 International License, which permits use, sharing, adaptation, distribution and reproduction in any medium or format, as long as you give appropriate credit to the original author(s) and the source, provide a link to the Creative Commons licence, and indicate if changes were made. The images or other third party material in this article are included in the article's Creative Commons licence, unless indicated otherwise in a credit line to the material. If material is not included in the article's Creative Commons licence and your intended use is not permitted by statutory regulation or exceeds the permitted use, you will need to obtain permission directly from the copyright holder. To view a copy of this licence, visit http://creativecommons.org/licenses/by/4.0/ The Creative Commons Public Domain Dedication waiver (http://creativecommons.org/publicdomain/zero/1.0/) applies to the data made available in this article, unless otherwise stated in a credit line to the data. 
coagulation and fibrinolysis activation [2]. Fibrinogen (FIB) and platelets (PLT) can also partly reveal the coagulation state of the patient. Previous studies have reported that pre-treatment plasma DD, FIB and PLT levels can predict prognosis in several types of malignancies, including ovarian [3], breast $[4,5]$, lung [6, 7], colorectal [8], gastric [9], and pancreatic cancers [10]. However, few studies have reported the use of preoperative DD levels to predict the prognosis of oral cancer. To the best of our knowledge, this is the first study to address the prognostic significance of perioperative DD, FIB and PLT levels and their relationship with clinicopathologic parameters in patients with OSCC.

\section{Methods}

\section{Patients}

This study was carried out at Guanghua Hospital of Stomatology, Sun Yat-sen University. All procedures involving human participants were approved by the hospital Ethics Committee, and written informed consent was obtained. We retrospectively reviewed cases from January 2015 to December 2018. Patients included in the study were pathologically confirmed oral squamous cell carcinoma cases without distant metastasis, and both primary and recurrent cases were analysed. Patients with any of the following criteria were excluded: 1) any other malignancy; 2) previously diagnosed venous thromboembolic diseases; 3) unstable angina; 4) severe infection; 5) history of anticoagulant drug use within 2 weeks before surgery; and 6) patients diagnosed with primary OSCC who had already received previous anti-cancer treatment. Finally, a total of 202 cases were included, and TNM classification was established according to the Union for International Cancer Control (UICC) 2015 guidelines. Preoperative plasma DD, FIB and PLT levels (measured within 1 week before surgery) and postoperative DD, FIB and PLT levels (measured $24 \mathrm{~h}, 48 \mathrm{~h}$ and $96 \mathrm{~h}$ after surgery) were collected. Other demographic and clinical information collected included age, sex, tumour location, TNM staging, treatment type, surgical duration, and postoperative adverse effects.

\section{Treatment and follow-up}

Patients were prescribed different treatment schedules according to the 2015 version of the NCCN guidelines for head and neck cancer. Patient follow-up was conducted at three-month intervals for the first 3 years after surgery and then every 6 months until April 2019 until disease progression, death, or loss to follow-up. The study was carried out either by patient follow-up visit or telephone follow-up at each scheduled time.
Table 1 Demographic and clinical characteristics of the patients

\begin{tabular}{|c|c|c|}
\hline Clinical characteristic & Category & $N(\%)$ \\
\hline \multirow[t]{2}{*}{ Sex } & Male & $148(73.3)$ \\
\hline & Female & $54(26.7)$ \\
\hline \multirow[t]{2}{*}{ Age(years) } & $<60$ & $130(64.4)$ \\
\hline & $\geq 61$ & 72 (35.6) \\
\hline \multirow[t]{7}{*}{ Tumor site } & Tongue & $93(46.0)$ \\
\hline & Buccal mucosa & $33(16.3)$ \\
\hline & Gingiva & $40(19.8)$ \\
\hline & Floor of mouth & $18(8.9)$ \\
\hline & Palate & $8(4.0)$ \\
\hline & Lip & $4(2.0)$ \\
\hline & Lymph node in the neck & $6(3.0)$ \\
\hline \multirow[t]{5}{*}{ T stage } & T1 (primary) & $29(14.36)$ \\
\hline & T2(primary) & $53(26.24)$ \\
\hline & T3(primary) & $26(12.87)$ \\
\hline & T4(primary) & $47(23.27)$ \\
\hline & Relapse \& metastasis & $47(23.27)$ \\
\hline \multirow[t]{2}{*}{ N stage } & No(primary+relapse) & $95+28(60.89)$ \\
\hline & $\mathrm{N}+($ primary+relapse) & $60+19(39.11)$ \\
\hline \multirow[t]{5}{*}{ Clinical stage } & I & $25(12.38)$ \\
\hline & $\|$ & $40(19.80)$ \\
\hline & III & $25(12.38)$ \\
\hline & IV & $65(32.18)$ \\
\hline & Relapse & $47(23.27)$ \\
\hline \multirow[t]{2}{*}{ Primary or relapse } & Primary & $155(76.73)$ \\
\hline & Relapse & $47(23.27)$ \\
\hline \multirow{2}{*}{$\begin{array}{l}\text { Preoperative D-dimer } \\
(\mu \mathrm{g} / \mathrm{L})\end{array}$} & Median & 358.47 \\
\hline & First and third quality & $184.36,581.74$ \\
\hline \multirow{2}{*}{$\begin{array}{l}\text { Preoperative FIB } \\
(g / L)\end{array}$} & Median & 3.56 \\
\hline & First and third quality & $2.88,4.08$ \\
\hline \multirow{2}{*}{$\begin{array}{l}\text { Preoperative PLT } \\
(10 \wedge 9 / L)\end{array}$} & Median & 246.5 \\
\hline & First and third quality & $210.00,305.00$ \\
\hline
\end{tabular}

Progression-free survival (PFS) was chosen as the study endpoint and was defined as the interval from surgery to local or distant relapse and/or metastasis, whichever occurred first. Survival time was considered censored if the patients died, were lost to follow-up, or were progression-free at the end of the study.

\section{Statistical analysis}

Quantitative data are described by the mean (range), and qualitative data are described as counts and percentages. The $x^{2}$ test was used to evaluate the association between clinicopathologic parameters and preoperative plasma DD, FIB and PLT levels. PFS was estimated by the Kaplan-Meier method, and differences in various 
Table 2 Correlation between plasma DD, FIB, PLT levels and patient/tumor characteristics in OSCC cases

\begin{tabular}{|c|c|c|c|c|c|c|c|c|c|}
\hline \multirow[t]{2}{*}{ Variables } & \multicolumn{3}{|c|}{ Preoperative DD $(\mu \mathrm{g} / \mathrm{L})$} & \multicolumn{3}{|c|}{ Preoperative FIB (g/L) } & \multicolumn{3}{|c|}{$\begin{array}{l}\text { Preoperative PLT } \\
(10 \wedge 9 / L)\end{array}$} \\
\hline & $<500$ & $\geq 500$ & $P$ & $<3.33$ & $\geq 3.33$ & $P$ & $<259.5$ & $\geq 259.5$ & $P$ \\
\hline Sex & & & 0.187 & & & 0.025 & & & 0.114 \\
\hline Male & 105 & 43 & & 51 & 97 & & 78 & 63 & \\
\hline Female & 34 & 20 & & 28 & 26 & & 40 & 21 & \\
\hline Age & & & 0.062 & & & 0.070 & & & 0.415 \\
\hline$<60$ & 92 & 33 & & 55 & 70 & & 70 & 53 & \\
\hline$\geq 60$ & 47 & 30 & & 24 & 53 & & 47 & 32 & \\
\hline Tumor site & & & 0.040 & & & 0.387 & & & 0.048 \\
\hline Tongue & 74 & 19 & & 42 & 51 & & 58 & 28 & \\
\hline Buccal mucosa & 18 & 15 & & 12 & 21 & & 18 & 11 & \\
\hline Gingiva & 23 & 17 & & 13 & 27 & & 22 & 25 & \\
\hline Floor of mouth & 14 & 4 & & 8 & 10 & & 11 & 9 & \\
\hline Palate & 4 & 4 & & 1 & 7 & & 1 & 7 & \\
\hline Lip & 2 & 2 & & 2 & 2 & & 1 & 1 & \\
\hline Neck (LN) & 4 & 2 & & 1 & 5 & & 6 & 4 & \\
\hline T stage & & & 0.000 & & & 0.129 & & & 0.194 \\
\hline T1 (primary) & 26 & 3 & & 14 & 15 & & 15 & 9 & \\
\hline T2(primary) & 39 & 14 & & 21 & 32 & & 36 & 16 & \\
\hline T3(primary) & 23 & 3 & & 11 & 15 & & 14 & 7 & \\
\hline T4(primary) & 30 & 17 & & 22 & 25 & & 30 & 28 & \\
\hline Relapse & 21 & 26 & & 11 & 36 & & 23 & 24 & \\
\hline $\mathrm{N}$ stage & & & 0.001 & & & 0.002 & & & 0.167 \\
\hline No(Primary) & 75 & 20 & & 34 & 61 & & 56 & 28 & \\
\hline $\mathrm{N}+($ Primary) & 43 & 17 & & 34 & 26 & & 39 & 32 & \\
\hline No(Relapse) & 12 & 16 & & 9 & 19 & & 15 & 13 & \\
\hline $\mathrm{N}+$ (Relapse) & 9 & 10 & & 2 & 17 & & 8 & 11 & \\
\hline Clinical stage & & & 0.000 & & & 0.094 & & & 0.040 \\
\hline I & 22 & 3 & & 11 & 14 & & 14 & 3 & \\
\hline$\|$ & 30 & 10 & & 15 & 25 & & 27 & 10 & \\
\hline III & 21 & 4 & & 10 & 15 & & 13 & 12 & \\
\hline IV & 45 & 20 & & 32 & 33 & & 41 & 35 & \\
\hline Relapse & 21 & 26 & & 11 & 36 & & 23 & 24 & \\
\hline Primary/Relapse & & & 0.000 & & & 0.012 & & & 0.113 \\
\hline Primary & 118 & 37 & & 68 & 87 & & 96 & 59 & \\
\hline Relapse & 21 & 26 & & 11 & 36 & & 23 & 24 & \\
\hline
\end{tabular}

prognostic factors were analysed by Cox regression analysis. Univariate analysis was used to identify significant prognostic predictors for PFS, and factors with $P$ values of $<0.1$ were subjected to multivariate analysis for PFS by Cox proportional hazard analysis. $P$ values $<0.05$ were regarded as statistically significant. All confidence intervals were set as $95 \%$ confidence levels. All statistical calculations were conducted by SPSS version 20.0.

\section{Results}

\section{Patient characteristics}

We collected a total of 202 cases in this retrospective study, including 148 males and 54 females, with a mean age of 56.3 (median 56, range 25-89) years old. Of the 202 patients, 155 had primary OSCC in our department, and the remaining 47 had recurrent lesions after surgical treatment in other medical institutions. The mean 

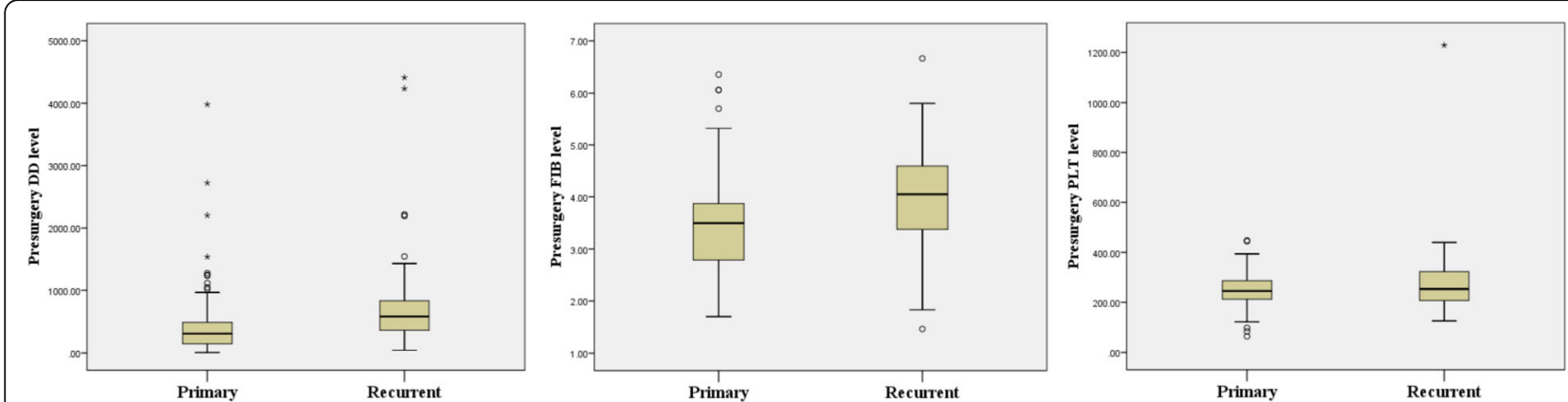

Fig. 1 The difference of DD, FIB and PLT levels between primary and recurrent OSCC. $P=0.018,0.038$ and 0.062 , respectively

follow-up period was 13.62 (median 10 , range 1 to 56 ) months. The clinical parameters of all 202 patients are shown in Table 1, with all the details in the Supplementary file.

\section{Relationship between preoperative plasma DD, FIB, and} PLT levels and clinicopathologic parameters

Of the 202 patients, preoperative FIB and PLT levels were closely related to each other $(r=0.376, P=0.000)$; however, the preoperative DD level and preoperative FIB and PLT levels were not significantly related $(P=0.053$ and 0.636 , respectively).

Preoperative plasma DD, FIB, and PLT levels and clinicopathologic parameters, including age, sex, tumour location, TNM staging, surgical treatment and duration, are summarized in Table 2. The mean preoperative DD level was $499.45 \mu \mathrm{g} / \mathrm{L}$, and referring to the manufacturer's recommendation, a plasma DD level of $500 \mu \mathrm{g} / \mathrm{L}$ was set as the cut-off value for normal and high DD values. The mean preoperative FIB and PLT levels were $3.33 \mathrm{~g} / \mathrm{L}$ and $259.5^{*} 10^{\wedge} 9 / \mathrm{L}$, respectively, and were set as cut-off values for low and high FIB and PLT values, respectively. In this study, we found that the preoperative DD level in different sex or age groups of patients was not statistically different $(P=0.187$ and 0.062 , respectively); however, in different tumour sites and in different $\mathrm{T}$ stage, $\mathrm{N}$ stage, and clinical stage patients, the preoperative DD level was significantly different $(P=0.040$, $0.000,0.001$ and 0000 , respectively). However, with regard to preoperative FIB and PLT levels, we found different results: the preoperative FIB level was different based on sex and $\mathrm{N}$ stage category only $(P=0.025$ and 0.002 , respectively), and the preoperative PLT level was different based on tumour site and clinical stage category only ( $P=0.048$ and 0.040 , respectively).
The means of DD, FIB and PLT in patients with primary oral cancer were $424.96 \mu \mathrm{g} / \mathrm{L}, 3.49 \mathrm{~g} / \mathrm{L}$ and $249.11^{*} 10^{\wedge} 9 / \mathrm{L}$, respectively, and those in patients with recurrent tumours were $752.07 \mu \mathrm{g} / \mathrm{L}, 3.82 \mathrm{~g} / \mathrm{L}$ and $283.72 * 10^{\wedge} 9 / \mathrm{L}$, respectively. The difference in DD and FIB levels between primary and recurrent cancer was statistically significant $(P=0.018$ and 0.038 , respectively) (Fig. 1).

\section{Relationship between postoperative DD change and treatment-related parameters}

We retrospectively observed postoperative DD levels in the first 3 days after surgery and in 96 patients with postoperative DD results. The postoperative DD level was elevated in all 96 patients on the first day after surgery and slowly decreased with time. The elevated level was correlated with the preoperative DD level $(r=0.284$, $P=0.005)$ as well as the surgical type $(\mathrm{r}=0.344, P=$ $0.001)$ but not the duration of surgery $(P=0.244)$ (Table 3).

\section{Survival analysis of patients with primary OSCC}

According to the NCCN guidelines and patient desire, 155 patients with primary OSCC were prescribed to different surgical plans including 1) excision of the primary lesion (19.4\%); 2) excision of the primary lesion and neck dissection $(25 \%)$; 3) excision of the primary lesion and vascularized free flap transplantation $(0.9 \%) ; 4)$ excision of the primary lesion, neck dissection and vascularized free flap transplantation (51.9\%); and 5) unoperated (2.8\%). Of the 155 patients with primary oral cancer, recurrence was diagnosed in 33 patients after surgical treatment in our department, rated $21.29 \%$, and 26 of them died during the follow-up time. The time from surgery to disease progression ranged from 1 to 34

Table 3 Correlation between postoperative DD change and treatment related characters

\begin{tabular}{|c|c|c|c|c|c|c|}
\hline & \multicolumn{2}{|c|}{ Preoperative DD } & \multirow{2}{*}{$\begin{array}{l}\text { Surgery type } \\
\text { r }\end{array}$} & \multicolumn{3}{|c|}{ Time consuming of surgery } \\
\hline & $r$ & $P$ & & $P$ & $r$ & $P$ \\
\hline Postoperative DD & 0.284 & 0.005 & 0.344 & 0.001 & 0.132 & 0.244 \\
\hline
\end{tabular}


Table 4 Univariate and multivariate analysis for disease-free survival of patients with primary OSCC

\begin{tabular}{|c|c|c|c|c|}
\hline \multirow[t]{2}{*}{ Variables } & \multicolumn{2}{|l|}{ Univariate analysis } & \multicolumn{2}{|c|}{ Multivariate analysis } \\
\hline & $\mathrm{HR}(95 \% \mathrm{Cl})$ & $P$ & HR $(95 \% \mathrm{Cl})$ & $P$ \\
\hline Sex & & 0.466 & & \\
\hline Male & 1.00 & & & \\
\hline Female & $0.73(0.32-1.69)$ & & & \\
\hline Age(years) & & 0.834 & & \\
\hline$<60$ & 1.00 & & & \\
\hline$\geq 60$ & $1.08(0.52-2.23)$ & & & \\
\hline T stage & & 0.884 & & \\
\hline $\mathrm{T} 1 \sim \mathrm{T} 2$ & 1.00 & & & \\
\hline T3 T4 & $1.05(0.53-2.08)$ & & & \\
\hline N stage & & 0.003 & & 0.007 \\
\hline No & 1.00 & & 1.00 & \\
\hline N1 & $0.68(0.20-2.38)$ & 0.548 & $0.723(0.21-2.55)$ & 0.619 \\
\hline N2 & $2.20(1.05-4.57)$ & 0.036 & $2.46(1.16-5.23)$ & 0.019 \\
\hline N3 & $33.94(3.65-315.9)$ & 0.002 & $19.34(2.00-186.96)$ & 0.010 \\
\hline Clinical stage & & 0.499 & & \\
\hline $\mid \sim \|$ & 1.00 & & & \\
\hline III IV & $1.29(0.62-2.72)$ & & & \\
\hline Pre. D-dimer & & 0.033 & & 0.056 \\
\hline$<500 \mu \mathrm{g} / \mathrm{L}$ & 1.00 & & 1.00 & \\
\hline$\geq 500 \mu \mathrm{g} / \mathrm{L}$ & $2.10(1.06-4.16)$ & & $1.98(0.98-3.97)$ & \\
\hline Pre. FIB & & 0.097 & & 0.100 \\
\hline$<3.33 \mathrm{~g} / \mathrm{L}$ & 1.00 & & 1.00 & \\
\hline$\geq 3.33 \mathrm{~g} / \mathrm{L}$ & $1.88(0.89-3.95)$ & & $1.94(0.88-4.26)$ & \\
\hline Pre. PLT & & 0.699 & & \\
\hline$<259.5^{*} 10^{\wedge} 9 / \mathrm{L}$ & 1.00 & & & \\
\hline$\geq 259.5^{*} 10^{\wedge} 9 / \mathrm{L}$ & $0.86(0.40-1.84)$ & & & \\
\hline Surgical type & & 0.732 & & \\
\hline 1 & 1.00 & & & \\
\hline 2 & $1.40(0.57-3.44)$ & 0.461 & & \\
\hline 3 & $1.53(0.70-3.34)$ & 0.284 & & \\
\hline 4 & $0.00(0.00-)$ & 0.983 & & \\
\hline Post.DD change & & 0.791 & & \\
\hline$<1000 \mu \mathrm{g} / \mathrm{L}$ & 1.00 & & & \\
\hline$\geq 1000 \mu \mathrm{g} / \mathrm{L}$ & $1.16(0.39-3.46)$ & & & \\
\hline Post. PLT change & & 0.622 & & \\
\hline$<60^{*} 10 \wedge 9 / \mathrm{L}$ & 1.00 & & & \\
\hline$\geq 60 * 10 \wedge 9 / \mathrm{L}$ & $1.22(0.55-2.74)$ & & & \\
\hline
\end{tabular}

months. Univariate analyses revealed that $\mathrm{N}$ stage $(P=$ $0.003)$ and preoperative DD level $(P=0.033)$ were predictors of PFS. In multivariate analysis, only $\mathrm{N}$ stage was found to be an independent prognostic factor in patients with primary OSCC $(P=0.007)$ (Table 4 , Fig. 2$)$.

In our study, PFS was $78.7 \%$. Patients with normal preoperative DD $(<500 \mu \mathrm{g} / \mathrm{L})$ had a significantly better PFS than patients with high preoperative DD $(\geq 500 \mu \mathrm{g} / \mathrm{L})$ (81.7\% vs. $74.2 \%, P=0.027$ ).

The data that support the findings of this study are available from the corresponding author upon reasonable request.

\section{Discussion}

In this study, we evaluated the relationship between preoperative DD, FIB, and PLT levels and the clinicopathological characteristics of OSCC, as well as the prognostic effect of preoperative DD, FIB and PLT. To the best of our knowledge, this is the first study to address this issue. We found that preoperative DD was significantly different in patients with OSCC with different primary sites or clinical stages, and DD could serve as an independent prognostic factor for patients with OSCC.

However, preoperative FIB and PLT did not show such strong predictive effects. Previous studies have reported that preoperative DD, FIB and PLT have certain prognostic value in several types of cancer [11], including small cell lung cancer [7], hepatocellular carcinoma [6], pancreatic adenocarcinoma [10], gastric cancer [12], and melanoma [13]. PLT was found to contribute to cancer progression through both thrombin-dependent and thrombin-independent mechanisms [14]. FIB is important in blood clotting, fibrinolysis and cellular and matrix interactions [15]. Zheng $\mathrm{S}$ et al. found that FIB can enhance PLT adhesion to tumour cells, and PLT in turn can release thrombin and facilitate FIB aggregation [16]. However, unlike most studies of DD, which set the cutoff value to $500 \mathrm{ng} / \mathrm{L}$, there were no consistent cut-off values of FIB and PLT in most of the studies. Hou C et al. [7] set the cut-off values of FIB and PLT as $2.75 \mathrm{~g} /$ $\mathrm{L}$ and $215^{*} 10^{\wedge} 9 / \mathrm{L}$, respectively, and they found a marginally significant relationship between elevated PLT and unfavourable PFS $(P=0.05)$ and no prognostic role for FIB. Liu Z and Liu P $[6,10]$ used $4.0 \mathrm{~g} / \mathrm{L}$ as the cut-off value for FIB and $300^{*} 10^{\wedge} 9 / \mathrm{L}$ for PLT, and both were significantly correlated with overall survival $(P<0.001$ and $P=0.010$, respectively). In a study by Holzinger et al. [17], $447 \mathrm{mg} / \mathrm{dL}$ was set as the cut-off value for FIB in patients with oral and oropharyngeal cancer, and elevated FIB was associated with poor overall survival $(P=$ $0.005)$ and recurrence-free survival $(P=0.008)$. In our study, the cut-off values of FIB and PLT were set as the mean value $\left(3.33 \mathrm{~g} / \mathrm{L}\right.$ and $259.5^{*} 10^{\wedge} 9 / \mathrm{L}$, respectively). We did find that the FIB level was significantly different between primary and recurrent OSCC, and yet in the survival analysis for primary OSCC, no significant predictive value for PFS was found. We supposed that the inconsistent result between our study and previous studies might be tumour type specific or can partly be attributed to the different sensitivities and different cut-off values of FIB and PLT in different articles. 

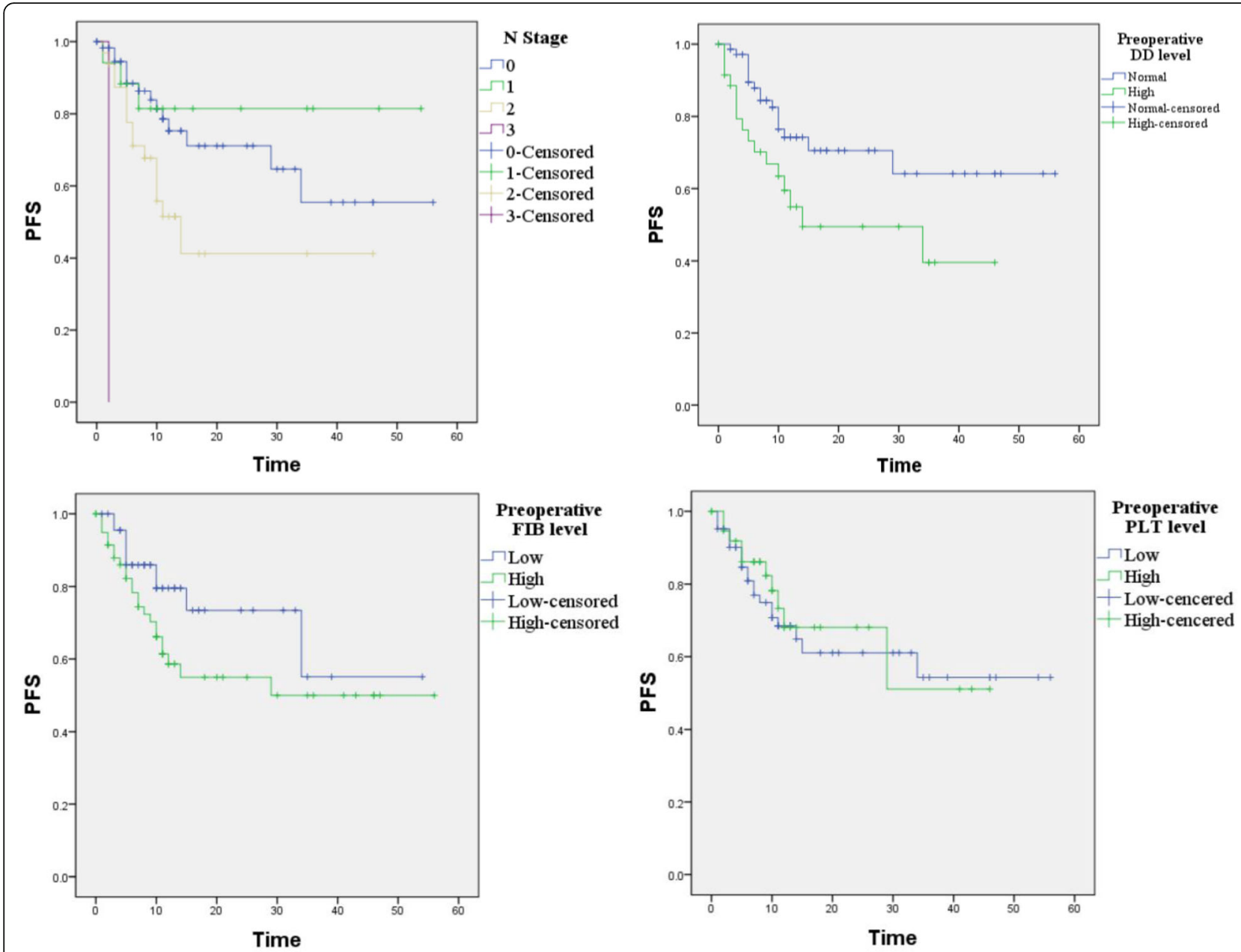

Fig. 2 Survival analysis of primary OSCC patients. $P=0.003,0.033,0.097$ and 0.699 , respectively

Cervical lymph node metastasis is the main prognostic factor for patients with OSCC, and neck dissection is an important and effective treatment. However, the complications of neck dissection are severe and significantly lower patients' quality of life. For $\mathrm{cT}_{1,2} \mathrm{~N}_{0}$ OSCC patients, even in the NCCN guidelines, there are no definite instructions about performing neck dissection. In this study, the preoperative DD level was found to be significantly correlated with $\mathrm{N}$ stage and could serve as an independent prognostic factor for patients with OSCC. Thus, we suggest that a high preoperative DD level may serve as an indicator for synchronous neck dissection in patients with $\mathrm{T}_{1,2}$ OSCC.

It is well known that surgical trauma is associated with coagulation, and Friedrich found that DD increased at the end of surgery and remained increased $24 \mathrm{~h}$ after surgery [18]. To further reveal the trauma caused by surgical treatment in patients with OSCC, we evaluated the postoperative DD levels and found that postoperative DD was markedly elevated within $24 \mathrm{~h}$ and then decreased slowly with time if there were no adverse effects, such as local or general infection or venous thrombosis. Moreover, the rising DD significantly correlated with surgical type but not the duration of surgery. In particular, patients who underwent the most extensive surgery had the highest elevation of postoperative DD level, suggesting that surgical trauma is correlated with the extent of surgery but not the duration of surgery. A relationship between elevated DD and local or general infection and deep vein thrombosis (DVT) was not found in our study, as limited cases developed infection (6/202) and DVT $(1 / 202)$ after surgery. We also investigated the postoperative DD level with PFS and found that it did not predict PFS.

\section{Conclusions}

DD is an easily measured and reproducible molecular marker. Plasma DD can be routinely measured prior to operations in various hospitals. In this study, we found that high preoperative DD level was significantly correlated with the more advance $\mathrm{T}$ and $\mathrm{N}$ stage, relapse cases as well as poor PFS in patients with OSCC. We 
suggest that a high preoperative DD level may serve as an indicator for synchronous neck dissection in patients with $\mathrm{T}_{1,2}$ OSCC and that continuous DD monitoring can be used in OSCC patient follow-up. Certainly, prospective studies and further studies with larger sample sizes are needed to confirm these findings. In addition, postoperative DD can partly reflect surgical trauma and postoperative adverse effects such as infection or venous thrombosis. Therefore, we suggest that preoperative and postoperative DD can be obtained as part of routine care for patients with OSCC.

\section{Supplementary Information}

The online version contains supplementary material available at https://doi. org/10.1186/s12885-021-07841-5.

Additional file 1.

\section{Abbreviations}

DD: D-Dimer; FIB: Fibrinogen; PLT: Platelets; OSCC: Oral squamous cell carcinoma; PFS: Progression-free survival; UICC: Union for International Cancer Control; NCCN: National Comprehensive Cancer Network

\section{Acknowledgements}

We thank Xiao Dongtao from the clinical laboratory, Guanghua Hospital of Stomatology, Sun Yat-sen University, for providing results from DD, FIB, and PLT testing.

\section{Authors' contributions \\ $\mathrm{YL}, \mathrm{XL}$ and $\mathrm{GL}$ conceived and designed the experiments. $\mathrm{YL}$ and $\mathrm{XM}$ contributed to the acquisition of data and performed the experiments. SZ contributed to patient follow-up. BZ and LY analysed and interpreted the data. $Y L$ wrote the paper. $X L$ and $G L$ revised the manuscript and gave final approval of the version to be published. All authors read and approved the final manuscript.}

\section{Funding}

This study is supported by a grant from the 5010 Clinical Medical Research Project of Sun Yat-sen University, grant number: 2010018. The funder had no role in the design of the study; collection, analysis, interpretation of the data; or writing of the manuscript.

\section{Availability of data and materials}

The dataset supporting the conclusions of this article is included within the article and its additional file.

\section{Ethics approval and consent to participate}

This study was approved by the Ethics Committee of Guanghua Hospital of Stomatology, Sun Yat-sen University. Written informed consent was obtained from all participants included in the study, with the approval number signed as 2011-02.

\section{Consent for publication}

Not applicable.

\section{Competing interests}

The authors declare that they have no competing interests.

\section{Author details}

'Department of Oral and Maxillofacial Surgery, Guanghua School of Stomatology, Hospital of Stomatology, Sun Yat-sen University, 56 Lingyuanxi Road, Guangzhou 510055, Guangdong, China. ${ }^{2}$ Guangdong Provincial Key Laboratory of Stomatology, No. 74, 2nd Zhongshan Road, Guangzhou 510080, Guangdong, China.
Received: 30 June 2020 Accepted: 26 January 2021

Published online: 05 February 2021

\section{References}

1. Jemal A, Siegel R, Ward E, Murray T, Xu J, Thun MJ. Cancer statistics, 2007. CA Cancer J Clin. 2007;57:43-66.

2. Adam SS, Key NS, Greenberg CS. D-dimer antigen: current concepts and future prospects. Blood. 2009;113:2878-87.

3. Man Y, Wang Y, Hao J, Liu X, Liu C, Zhu C, et al. Pretreatment plasma Ddimer, fibrinogen, and platelet levels significantly impact prognosis in patients with epithelial ovarian cancer independently of venous thromboembolism. Int J Gynecol Cancer. 2015;25:24-32.

4. Batschauer AP, Figueiredo CP, Bueno EC, Ribeiro MA, Dusse LM, Fernandes AP, et al. D-dimer as a possible prognostic marker of operable hormone receptor negative breast cancer. Ann Oncol. 2010;21:1267-72.

5. Ghadhban BR. Plasma d-dimer level correlated with advanced breast carcinoma in female patients. Ann Medic Surg. 2018;36:75-8.

6. Liu Z, Guo H, Gao F, Shan Q, Li J, Xie H, et al. Fibrinogen and D-dimer levels elevate in advanced hepatocellular carcinoma: high pretreatment fibrinogen levels predict poor outcomes. Hepatol Res. 2017;47:1108-17.

7. Hou C, Jiang F, Ma H, Zhu Q, Wang Z, Zhao B, et al. Prognostic role of preoperative platelet, fibrinogen, and D-dimer levels in patients with nonsmall cell lung cancer: a multicenter prospective study. Thorac Cancer. 2019; 10:304-11.

8. Yamamoto M, Yoshinaga K, Matsuyama A, Iwasa T, Osoegawa A, Tsujita E, et al. Plasma D-dimer level as a mortality predictor in patients with advanced or recurrent colorectal cancer. Oncology. 2012;83:10-5.

9. Go SI, Lee MJ, Lee WS, Choi HJ, Lee US, Kim RB, et al. D-dimer can serve as a prognostic and predictive biomarker for metastatic gastric cancer treated by chemotherapy. Medicine (Baltimore). 2015;94:e951.

10. Liu P, Zhu Y, Liu L. Elevated pretreatment plasma D-dimer levels and platelet counts predict poor prognosis in pancreatic adenocarcinoma. Onco Targets Ther. 2015;8:1335-40.

11. Li W, Tang Y, Song Y, Chen S, Sisliyan N, Ni M, et al. Prognostic role of pretreatment plasma D-dimer in patients with solid tumors: a systematic review and meta-analysis. Cell Physiol Biochem. 2018;45:1663-76.

12. Kanda M, Tanaka C, Kobayashi D, Mizuno A, Tanaka Y, Takami H, et al. Proposal of the coagulation score as a predictor for short-term and longterm outcomes of patients with Resectable gastric Cancer. Ann Surg Oncol. 2017;24(2):502-9.

13. Anna D, Christoffer G, Jochen U, Stefan WS. D-dimers in malignant melanoma: association with prognosis and dynamic variation in disease progress. Int J Cancer. 2017;140:914-21.

14. Camerer E, Qazi AA, Duong DN, Cornelissen I, Advincula R, Coughlin SR. Platelets, protease-activated receptors, and fibrinogen in hematogenous metastasis. Blood. 2004;104:397-401.

15. Mosesson MW. Fibrinogen and fibrin structure and functions. J Thromb Haemost. 2005:3(8):1894-904.

16. Zheng S, Shen J, Jiao Y, Liu Y, Zhang C, Wei M, et al. Platelets and fibrinogen facilitate each other in protecting tumor cells from natural killer cytotoxicity. Cancer Sci. 2009;100:859-65.

17. Holzinger D, Danilovic I, Seemann R, Kornek G, Engelmann J, Pollerstorff R, et al. Prognostic impact of pretreatment plasma fibrinogen in patients with locally advanced oral and oropharyngenl cancer. PLOS ONE. 11(6): e0158697.

18. Friedrich MJ, Schmolders J, Rommelspacher Y, Strauss A, Ruhl H, Mayer G, et al. Activity pattern analysis indicates increased but balanced systemic coagulation activity in response to surgical trauma. TH Open. 2018;2(4): e350-6.

\section{Publisher's Note}

Springer Nature remains neutral with regard to jurisdictional claims in published maps and institutional affiliations. 